\title{
Formação matemática do professor polivalente: \\ um estudo metanalítico
}

\section{Bárbara Cristina Moreira Sicardi Nakayama}

Jaqueline Ferreira da Silva²

\section{Resumo}

A finalidade deste estudo foi responder: Quais percepçôes sobre formação e conhecimento matemático parecem fundamentar as pesquisas que discutem a formação matemática do professor polivalente? Os objetivos são: viabilizar o entendimento de que ao discutir a formação matemática oferecida nos cursos de Pedagogia se está problematizando a formação do profissional que atua no contexto polivalente; Caracterizar o movimento de apropriação de repertórios e saberes relacionados ao conhecimento matemático desse profissional docente. A coleta de dados ocorreu a partir do mapeamento de pesquisas publicadas no Encontro Nacional de Educação Matemática (ENEM) e no Simpósio Internacional de Educação Matemática (SIPEM) que versam sobre a formação matemática do professor polivalente e por fim a metanálise. Os resultados indicam: grande variedade de pontos de vista na formação matemática do professor polivalente; tendência em privilegiar aspectos metodológicos da Matemática; preocupação declarada com a modificação das crenças e concepçóes dos futuros professores sobre a Matemática, seu ensino-aprendizagem.

Palavras-chave: Formação Matemática. Ensino de Matemática. Pedagogia. Metanálise.

\begin{abstract}
The purpose of this study was to answer: Which perceptions about formation and mathematical knowledge seem to support the researches that discuss the mathematical formation of the polyvalent teacher? The objectives are: to make possible the understanding that when discussing the mathematical training offered in the courses of Pedagogy is being problematized the training of the professional that works in the polyvalent context; To characterize the movement of appropriation of repertoires and knowledge related to the mathematical knowledge of this teaching professional. Data collection was based on the mapping of research published in the National Meeting of Mathematics Education (ENEM) and the International Symposium on Mathematical Education (SIPEM), which deal with the mathematical formation of the polyvalent teacher and finally the meta-analysis. The results indicate: a great variety of points of view in the mathematical formation of the polyvalent teacher; Tendency to favor methodological aspects of Mathematics; Expressed concern with the modification of the beliefs and conceptions of future teachers about Mathematics, its teaching-learning.
\end{abstract}

Keywords: Mathematical formation. Mathematics Teaching. Pedagogy. Meta-analysis.

\footnotetext{
${ }^{1}$ Doutora em Educação (2008) pela Universidade Estadual de Campinas. Atualmente é professora na Universidade Federal de São Carlos - Campus Sorocaba, atuando em cursos de Licenciatura e no curso de Mestrado Acadêmico em Educação. E-mail: < barbara.sicardi@gmail.com>.

${ }^{2}$ Mestre em Educação pela Universidade Federal de São Carlos - campus - Sorocaba, na área de Educação Matemática e Formação de Professores. É coordenadora pedagógica da E.M.E.F "Prof Helena Rodrigues" como Coordenadora Pedagógica e vinculada aos grupos GEPRAEM - Grupo de Estudos e Pesquisas sobre Práticas Educativas em Matemática. NEPEN - Núcleo de Estudos e Pesquisas sobre Narrativas Educativas, Formação e Trabalho docente. E-mail: <jackfs28@ yahoo.com.br>.
} 


\section{Introdução}

Nesse texto são trazidos e discutidos, resumidamente, os resultados de um estudo que se propôs a examinar pesquisas que discutem a formação matemática do professor polivalente, a fim de perceber e analisar que aspectos e dimensóes vêm sendo destacados e privilegiados nessas produções, assim como problematizar questóes que emergiram a partir das referidas pesquisas. Dessa forma, essa pesquisa abrangeu estudos que foram feitos em diferentes contextos de formação do professor polivalente.

A coleta se restringiu a pesquisas divulgadas nos principais eventos da Educação Matemática sendo eles: Encontro Nacional de Educação Matemática (ENEM) e Simpósio Internacional de Educação Matemática (SIPEM).

A amostra consistiu em 28 trabalhos, constituindo artigos publicados nesses eventos no período de 2007 a 2015, que envolveram cursos de formação inicial ou continuada de professores para os anos iniciais que, de modo particular, abordaram aspectos relacionados ao ensino de matemática nos anos iniciais.

A questão que orientou a pesquisa foi: Quais percepçóes sobre formação e conhecimento matemático parecem fundamentar as pesquisas que discutem a formação matemática do professor polivalente? Tendo como objetivos:

- Viabilizar o entendimento de que ao discutir a formação matemática oferecida nos cursos de Pedagogia se está problematizando a formação do profissional que atua no contexto polivalente;

- Caracterizar o movimento de apropriação de repertórios e saberes relacionados ao conhecimento matemático desse profissional docente.

Este texto foi estruturado com seçôes destinadas à metodologia da pesquisa, ao caminho percorrido para a criação de categorias, para a análise e para as consideraçóes finais.

\section{Percurso metodológico}

De maneira ampla, analisou-se as pesquisas divulgadas nos principais eventos da Educação Matemática Encontro Nacional de Educação Matemática (ENEM) e Simpósio Internacional de Educação Matemática (SIPEM) que tenham tido como foco principal (ou um dos focos principais) algum ou alguns aspectos relacionados à formação matemática do professor polivalente. Dentre esses aspectos, podemos incluir estudos de disciplinas, cursos ou documentos legais, estudos realizados sobre ou com a participação dos futuros professores e seus formadores e, ainda, estudos que acompanham o desenvolvimento de cursos de formação inicial ou continuada.

O critério para escolha desses eventos se deu por esses serem considerados de grande relevância no campo da Educação Matemática e por agregar pesquisas que estão no âmbito dessa discussão.

Para alcançar o objetivo principal desta pesquisa, optou-se por realizar uma metanálise qualitativa dos artigos publicados nos eventos mencionados acima. A metanálise, segundo Fiorentini e Lorenzato (2006, p. 71) “[...] é uma revisão sistemática de outras pesquisas, visando realizar uma avaliação crítica das mesmas e/ou produzir novos resultados ou sínteses a partir do confronto desses estudos, transcendendo aqueles anteriormente obtidos.”. Entretanto, para realizar a metanálise, foi 
preciso primeiro, constituir o corpus de análise mediante mapeamento. Segundo esses autores, a metanálise qualitativa surge como modalidade de revisão sistemática de estudos de natureza qualitativa, podendo ser um estudo profundo, envolvendo um número reduzido de trabalhos investigativos. Os resultados podem ser integrativos, cruzados ou contrastados com o intuito de produzir resultados mais amplos ou gerais.

Tomando Firentini e Lorenzato (2006) como referencia, os passos seguidos para organização desta pesquisa foram: Problema/Objetivo (Definiçâo do campo específico), busca de documentos (Sites dos eventos), definição do corpus de análise (Definição do foco de estudo, seleção, fichamento), metanálise (Análise da análise, contraste/comparação, outras interpretaçóes e categorias analíticas) e síntese.

Antes da metanálise, ao definir o corpus de análise, com o objetivo de discutir o que as pesquisas trazem sobre conhecimentos matemáticos e formação matemática realizou-se um mapeamento.

Os descritores utilizados como critério para escolha dos trabalhos foram: polivalência / polivalente / anos iniciais / séries iniciais / ensino fundamental / anos iniciais da educação básica, encontrando 52 artigos relacionados. A partir disso, fez-se necessário uma primeira leitura dos títulos e dos resumos a fim de identificar, nos trabalhos expostos, aqueles que tinham por objeto a formação dos professores que ensinam Matemática na Educação Infantil e nos Anos Iniciais do Ensino Fundamental. Posteriormente, destacamos os dados mais específicos: problema da pesquisa, objetivos, metodologia e resultados alcançados. A pretensão era de identificar esses dados por meio de cada um dos resumos apresentados, no entanto, como alguns resumos náo os revelavam foi necessário ler os trabalhos na íntegra.

Nesse momento, foi preciso definir quais artigos encontrados contemplavam os objetivos dessa pesquisa. Para isso, foi feito fichamento das leituras dos artigos com alguns elementos considerados: objetivos, referencial teórico, procedimentos metodológicos de coleta e análise de dados e principais resultados. A partir desses fichamentos, foi possível perceber algumas semelhanças entre os trabalhos, permitindo uma primeira categorização. Dentre esses aspectos, podem-se incluir estudos de disciplinas, cursos ou documentos legais, estudos realizados sobre ou com participação de futuros professores e seus formadores.

Desse modo, a amostra que compóe o corpus da metanálise de forma a possibilitar um aprofundamento cuidadoso na análise dos trabalhos e o foco nos objetivos da pesquisa, constitui de 28 artigos publicados na forma de comunicação científica. Convém considerar que, não incluímos artigos que (i) tiveram como foco principal observar a prática do professor ou apresentação de recursos didáticos, (ii) um que se tratava de relato de experiência e outro que náo abarcava informaçóes no resumo consistente para compor a análise e o texto completo não estava disponível.

As informaçôes adquiridas foram categorizadas mediante mapeamento, organizadas, descritas e comparadas a fim de apresentarmos um balanço das pesquisas relacionadas à formação do professor polivalente, publicadas nos anais já enunciados.

Após leitura dos textos completos desses artigos. Houve uma primeira classificação do corpus de análise que constituiu no mapeamento das pesquisas que estáo apresentadas no quadro abaixo com o intuito de expor o foco de estudo de cada artigo escolhido. 
Quadro 1 - Categorias e critérios de inclusão

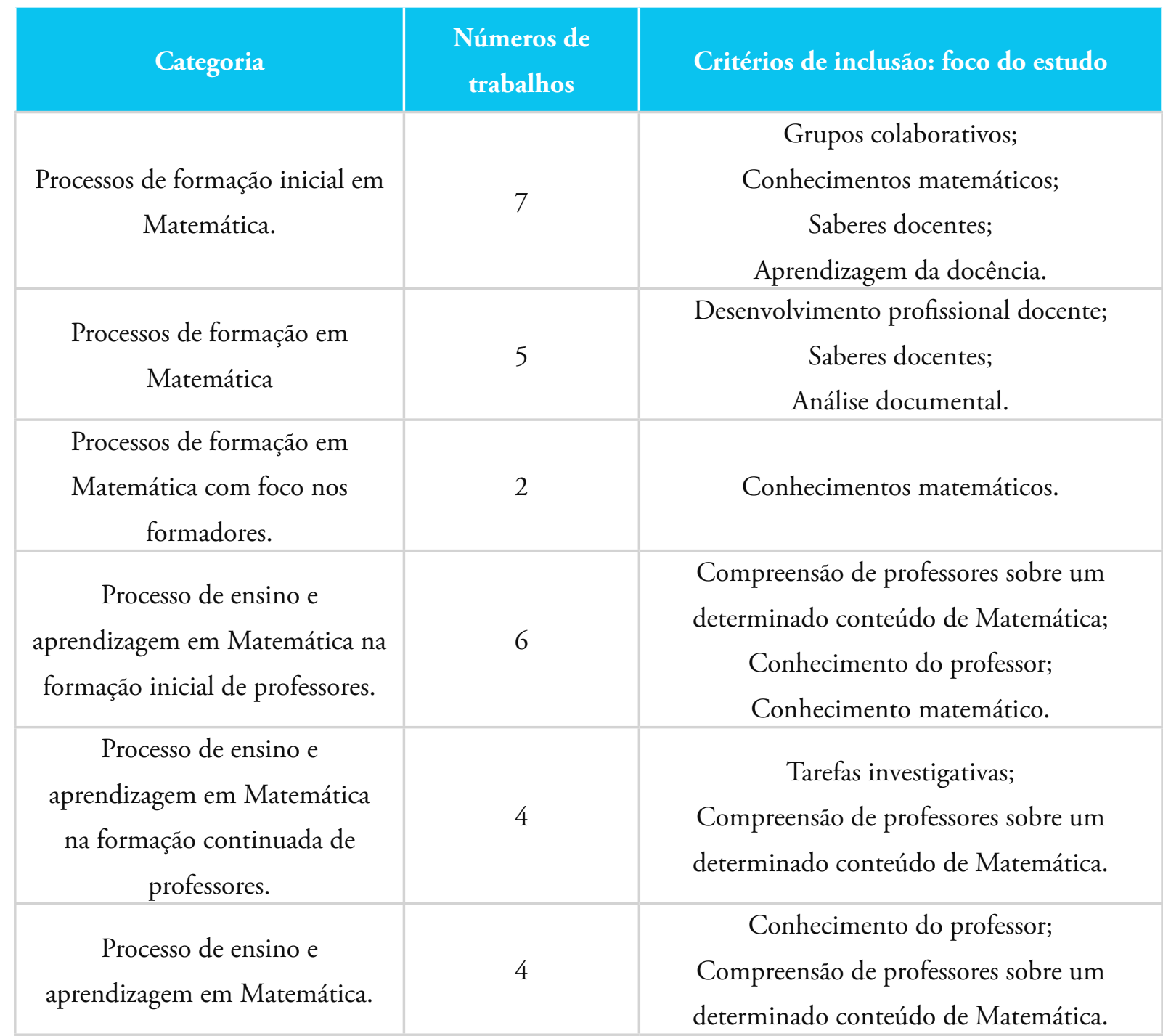

Estabelecido o conjunto de trabalhos, passou-se a identificar modalidades de análise. Esse processo permeou vários momentos de reflexão e inferências o que possibilitou identificar indícios de categorias que iam além dos estudos apresentados nos artigos.

Ao analisarmos o conteúdo das informações obtidas, nos trabalhos selecionados para esta pesquisa, identificamos duas diferentes categorias que emergiram das vozes dos autores dos artigos e do processo de metanálise.

Com base nos objetivos e questão desta dissertação, foram identificadas duas modalidades: pressupostos de conhecimentos matemáticos; pressupostos de processos de formação. Portanto a organização da metanálise construída para esta pesquisa foi definida partindo dessas duas modalidades e também dos resultados finais.

\section{A análise interpretativa}

Com as categorias formuladas e os trabalhos devidamente classificados, o próximo passo consistiu da análise cuidadosa das produçôes obtidas, e de confrontá-las com a literatura existente, a fim de dialogarmos com a questão de pesquisa. 
Em relação aos pressupostos de conhecimento matemático, percebe-se uma diversidade de interpretação propostas por esses pesquisadores em seus artigos. A maior influência, no rol desses trabalhos, são os estudos de Shulmann (1986).

Os autores Costa (2009), Quintas (2007), Cardoso, Curi (2010), Silva, Esteves, Souza (2010), Círiaco, Morelatti (2013) compreendem que o conhecimento matemático se desmembra em três vertentes: conhecimento do conteúdo da disciplina; conhecimento didático do conteúdo; conhecimento do currículo.

Carneiro, Passos, Lupiáńez (2012), trazem como pressuposto o conhecimento didático do conteúdo apresentados por Shulmann (1986), partem do princípio de que as resoluções de problemas são fundamentais para assimilação de conceitos matemáticos no indivíduo. Já Nogueira, Pavanello, Oliveira (2012), apresentam o conhecimento do conteúdo da disciplina e que para o ensino o professor que irá ensinar Matemática necessita ter conhecimentos filosófico, histórico e epistemológico.

Carvalho (2007), Bianchini, Nehring (2013) não expõem como referencial teórico as ideias de Shulmann (1986), mas deixam subentendido que versam sobre o conhecimento do conteúdo. Isso é possível de perceber quando trazem em suas pesquisas que o conhecimento matemático envolve um conjunto de saberes sendo eles: conceitos, algoritmos das operaçóes, compreensão do erro, blocos de conteúdos, domínio dos números, organização de dados, leituras de gráficos e análises estatísticas. Apresentam que esses conhecimentos são indispensáveis ao cidadão nos dias de hoje e em tempos futuros.

Sousa, Silva, Barreto (2010), abordam um conhecimento especifico da semiótica, destacando como uma atividade cognitiva é fundamental à aprendizagem de Matemática. Beline, Passos, Nagy, Cyrino (2010), discutem que o conhecimento matemático está atrelado a expressóes que não correspondem ao ensino de conteúdos matemáticos, no caso deste estudo, a expressão "vai um".

Bulos (2010) explicita os cinco conhecimentos matemáticos propostos por Shulmann (1986) sendo eles: do conteúdo da disciplina, do pedagógico geral, didático do conteúdo da disciplina, do currículo, dos contextos educacionais.

Soares (2013) apresenta as ideias de Shulmann, mas de um modo geral. Em seguida, o conhecimento cultural é destacado pelas pesquisas que estão no quadro. Nesses estudos, a ideia de conhecimento matemático, está relacionada a fenômenos que ocorrem no meio sócio-cultural e que os mesmos são permeados por crenças negativas em relação à Matemática que vão passando culturalmente pela sociedade, ocasionando insegurança e bloqueio na assimilação desse conhecimento, tanto por parte dos professores polivalentes quanto dos alunos da Educação Básica. Esse conhecimento se desenvolve na interação com o meio em que vive, tendo o professor como mediador dessa aprendizagem.

As influências de crenças são bem fortes nesses estudos, porém apresentam alternativas de como reverter atitudes negativas que muitos professores polivalentes têm da Matemática.

Logo depois, vemos os pressupostos baseados nos Documentos Oficiais, que segundo esses autores, abarca um conjunto de saberes, por meio de blocos de conteúdos apresentados nesses documentos, como: Número e operaçôes; Grandezas e Medidas; Espaço e Forma; Tratamento da informação. Esses documentos, segundo os autores exposto no quadro, agregam conhecimentos atitudinais, procedimentais e atitudinais para o ensino de Matemática. 
Essas pesquisas ao apresentar o pressuposto de conhecimento matemático, já apresentam como é organizado para o ensino. Segundo esses autores, entende-se que muitos professores não têm conhecimentos dos documentos oficiais. Portanto, ressaltam a necessidade de oferecer formação continuada para esses profissionais, com o objetivo de trazer reflexáo dos objetivos, do currículo e dos conteúdos específicos da Matemática.

Nas pesquisas que apresentam indícios de que o conhecimento matemático para o ensino de Matemática é adquirido por meio de conceitos. Palma, Moura (2010) apresentam-no, basicamente dessa forma: a problematização da formação matemática: o resgate das memórias escolares; o aprendizado da Matemática para poder ensinar: a resolução de atividades de ensino; a compreensão do aprender e ensinar Matemática; a análise de situações de ensino e pesquisa; a organização de processos de ensino e aprendizagem: elaboração, desenvolvimento e avaliação de uma atividade de ensino; produção de portfólio de sala de aula. Dias, Paiva, Sá (2013), definem que os conceitos matemáticos são constituídos ao longo do desenvolvimento cognitivo dos indivíduos e a partir de suas relações com o meio.

O estudo de Silva e Visolli (2013), é o único que apresenta um pressuposto seguindo a ideia de Ponte (1998), destacando que o conhecimento matemático para o professor que ensina Matemática engloba: ter bons conhecimentos e uma boa relação com a Matemática; conhecer em profundidade o currículo e ser capaz de recriar de acordo com a sua situação de trabalho; de conhecer o aluno e a aprendizagem; dominar os processos de instrução, os diversos métodos e técnicas, relacionando-os com os objetivos e conteúdos curriculares; conhecer bem o seu contexto de trabalho, nomeadamente a escola e seu sistema educativo; conhecer a si mesmo como profissional.

Na pesquisa de Pozzobon e Heck (2013), encontramos o pressuposto de conhecimento matemático baseado nos estudos de Piaget, que apresentando as etapas da aprendizagem da criança e os estágios de desenvolvimento propostos por este autor.

Esses pressupostos de conhecimentos matemáticos levantados nessas pesquisas revelam a postura que esses pesquisadores apresentam. Sendo implícitos ou explícitos, que esses conhecimentos estão relacionados ao domínio do conhecimento da Matemática, dando a idéia de que é preciso saber "muita Matemática" para ensiná-la. Percebe-se que há uma preocupaçâo em discutir este tipo de conhecimento para os professores polivalentes, procurando entender, problematizar e refletir sobre o desenvolvimento do ensino-aprendizagem de Matemática nos anos iniciais do Ensino Fundamental e de formação desses profissionais com a finalidade de promover mudanças nesse campo. Porém, é necessário, antes de tudo, questionar as dificuldades que esses professores enfrentam em administrar a polivalência, que vai além do ensino-aprendizagem.

Mediante as pesquisas analisadas, partindo da modalidade pressupostos de formação matemática, observamos dois eixos que esses estudos fundamentaram: um seria um ideal de como deveria ser essa formação e outro de como é priorizado o ensino de Matemática na formação de professores ou nos Anos Iniciais do Ensino Fundamental. Portanto, para maior compreensão, os quadros abaixo foram organizados: 
Quadro 2 - Apresentação do eixo: pressupostos de formação matemática com ideal de formação.

\begin{tabular}{|c|c|}
\hline $\begin{array}{l}\text { Pressupostos de formaçáo matemática com } \\
\text { ideal de formação }\end{array}$ & Artigos relacionados \\
\hline Formação prática e teórica & $\begin{array}{l}\text { Ciríaco, Morelatti (2013), Costa (2009), Costa } \\
\text { (2013), Oliveira (2009), Palma, Moura (2010), Soares } \\
\text { (2013) Tozetto, Brandt (2010), }\end{array}$ \\
\hline Práticas de reflexão & $\begin{array}{c}\text { Carneiro, Passos, Lupiánez (2012), Dias, Paiva, Sá } \\
\text { (2013), Palma, Moura (2010), Pozzobon, Heck } \\
\text { (2013), Silva, Esteves, Souza (2010) }\end{array}$ \\
\hline $\begin{array}{c}\text { Especialistas em Matemática atuando nos anos } \\
\text { iniciais do Ensino Fundamental }\end{array}$ & Nogueira, Pavanello, Oliveira (2012) \\
\hline $\begin{array}{l}\text { Priorizar a ruptura de paradigmas e crenças } \\
\text { relacionadas à Matemática }\end{array}$ & $\begin{array}{l}\text { Batista, Souza (2010), Carneiro (2015), Costa, Curi } \\
\text { (2010), Quintas (2007), Venâncio, Vianna (2010) }\end{array}$ \\
\hline $\begin{array}{l}\text { Priorizar o ensino do conhecimento didático do } \\
\text { conteúdo }\end{array}$ & $\begin{array}{c}\text { Bianchini, Nehring (2013), Bulos (2010), Cardoso, } \\
\text { Curi (2010), Carvalho (2007), Lima (2013), Sousa, } \\
\text { Bertucci, Sousa, Silva, Barreto (2010) }\end{array}$ \\
\hline
\end{tabular}

Por meio das leituras desses artigos de um modo geral, essas pesquisas mencionadas no quadro apontam que:

- O conhecimento matemático é atrelado à aspectos culturais que engessam a Matemática e que é responsabilidade dos formadores dos cursos de Pedagogia, quebrar com esses paradigmas, por meio de práticas de ensino diferenciadas;

- A importância de atrelar a teoria com a prática para criar oportunidades para os alunos de graduaçáo saberem o como e o porque ensinar matemática;

- A formação continuada em grupos colaborativos é pertinente para a constituição e desenvolvimento profissional em relação à Matemática.

- A prática de pesquisa em Educação Matemática na formação inicial, também é um importante meio para o desenvolvimento profissional e pedagógico dos professores polivalentes.

Essas propostas que esses autores expõem, vem de acordo com a metodologia de pesquisas que desenvolvem sendo em contextos de formaçáo, em que os próprios pesquisadores estão envolvidos.

Quadro 3 - Apresentação do eixo: pressupostos de como é o ensino de Matemática na formação de professores ou nos anos iniciais do Ensino Fundamental.

\section{Pressupostos de como é o ensino de Matemática \\ na formaçáo de professores ou nos anos iniciais do Ensino Fundamental.}

O ensino de Matemática é fragmentado

Lacuna na formação matemática

\section{Artigos relacionados}

Beline, Passos, Nagy, Cyrino (2010), Mandarino (2007), Silva, Vizolli (2013) 
Essas pesquisas indicam que a má formação dos professores polivalentes nos cursos de Pedagogia induz a um ensino de Matemática nos Anos Iniciais do Ensino Fundamental fragmentado. Na maioria das vezes com ênfase nas quatro operaçôes e com linguagem enraizada de concepções que não condiz com os conteúdos da Matemática como, por exemplo, no trabalho de Beline, Passos, Nagy, Cyrino (2010), que discute sobre a utilização do termo "vai um" no ensino de adição. Questionam o pouco tempo para formar esses profissionais. Afirmam que é durante as disciplinas voltadas a Matemática na formação inicial que há uma melhor interação com o conceito matemático, permitindo, na maioria das vezes, a aquisição do letramento matemático.

Pondera-se destacar os elementos apresentados nos resultados das pesquisas, dividindo-as por quantidades de pesquisas e por consideraçôes aproximadas:

Quadro 4 - Principais resultados.

\section{Principais resultados}

Crítica à formação inicial que prioriza o ensino de Matemática procedimental e não conceitual.

Defende a importância da relação entre teoria e prática

Defendem a importância dos formadores de professores terem experiências nos Anos Iniciais do Ensino Fundamental

Apresentam que boas práticas de ensino na formação inicial resultam em quebra de crenças em relação à Matemática e mobilização de saberes e domínio dos conteúdos.

Necessidade de diálogo entre os cursos de Pedagogia e Matemática.

Revela que existem poucos estudos que abordam essa temática, o que dificulta mudanças nesse campo.

Apresentam a formação continuada em grupos colaborativos como importante meio para mudanças positivas no ensino de Educação Matemática.

\section{Artigos relacionados}

Beline, Passos, Nagy, Cyrino (2010), Bulos (2010), Costa Curi (2010), Mandarino (2007), Soares

(2013), Sousa, Silva, Barreto (2010), Costa (2013), Palma, Moura (2010), Sousa, Bertucci (2010)

Lima (2013), Quintas (2007), Oliveira (2009)

Batista, Souza (2010), Carneiro (2015), Carneiro, Passos, Lupiáñez (2012), Dias, Paiva, Sá (2013) Costa (2009),Pozzobon, Heck (2013), Tozetto, Brandt (2010), Venâncio, Viana (2010) Cardoso, Curi (2010), Carvalho (2007), Nogueira, Pavanello, Oliveira (2012), Silva, Esteves, Souza (2010) Vasconcello, Bittar (2007)

Bianchini, Nehring (2013), Ciríaco, Morelatti (2013), Silva, Vizolli (2013)

Ao analisar o conteúdo dos resultados dessas pesquisas, percebe-se que a maior parte dos trabalhos envolveu diretamente a participação de estudantes de Pedagogia ou professores da Educação Básica. Esses resultados demonstraram que na maior parte das vezes, os conhecimentos matemáticos são ad- 
quiridos ao longo da vida escolar e que aspectos de natureza afetiva interferem tanto na aprendizagem quanto no ensino de Matemática.

Na pesquisa de Costa (2009) realizada com egressos de um curso de Pedagogia, o autor pontua que há insegurança desses sujeitos ao iniciar a carreira docente, principalmente, para lecionar Matemática. Portanto, defende a necessidade de interligar a teoria com a prática, para assim permitir a criaçáo de uma identidade com o ensino-aprendizagem de Matemática. Palma, Moura (2010), concluem que ao vivenciar a teoria nos cursos de Pedagogia e a prática do estágio o estudante se assume como aluno-professor. Pozzobon, Heck (2013) a formação do professor nos anos iniciais, tem se conduzido a partir de práticas de ensino com ênfase na construçáo do conhecimento, em práticas cognitivistas, em metodologias de ensino, produzindo efeitos na formação de professores na atualidade, como a impossibilidade de pensar outros jogos de verdade para a formação de professores de matemática e de colocar em questão as práticas que, por vezes, afastam os professores dos conhecimentos específicos de matemática.

Oliveira (2009), Quintas (2007), Soares (2013) sinalizam que além de ter pouca carga horária nos cursos de Pedagogia relacionada ao ensino de Matemática, os formadores desses professores precisam ter maior conhecimento do contexto escolar. Desse modo, abordar no curso assuntos que estáo mais próximos da realidade que esses estudantes irão enfrentar e que permita a reflexão e o desenvolvimento profissional. Lima (2013), atenta que simplesmente ampliar a carga horária nos cursos de Pedagogia náo significa garantia do aprofundamento de estudos em Matemática, depende mais da formação do formador que deve ter o domínio dos fundamentos históricos, epistemológicos e conceituais.

Batista, Souza (2010), reforçam que o bom trabalho na graduação de Pedagogia em relação à Matemática, contribui para mudanças na postura dos futuros professores polivalentes. Venâncio, Viana (2010), indicam que a partir de práticas promotoras de questionamentos, participação e estratégias para solucionar problemas, entre outros, favorecem o desenvolvimento da auto-estima e confiança em Matemática. Carneiro, Passos, Lupiáńez (2012), Carneiro (2015) e Costa, Curi (2010), Dias, Paiva, Sá (2013), concluem que proporcionar práticas reflexivas nos cursos de formação é necessário para que permita que os estudantes tenham acesso a conhecimentos sobre conteúdos específicos e conhecimentos pedagógicos. No caso do ensino de Matemática nos cursos de Pedagogia, garantir o contato com os fundamentos e questóes pedagógicas, permitindo quebras de crenças negativas relacionadas a essa ciência. Nessa mesma linha, Mandarino (2007), caracteriza que a má formação do professor polivalente, contribui para um ensino procedimental, por etapas e fragmentado. Sousa, Silva, Barreto (2010), Costa (2013), verificam a necessidade de um ensino com vistas a aprendizagem conceitual para ensinar Matemática, bem como a mobilização de saberes matemáticos que vão desde o domínio do objeto de estudo e seus processos de ensino.Bulos (2010), Beline, Passos, Nagy, Cyrino (2010) indicam a necessidade de formatação das disciplinas nos cursos de Pedagogia.

Na questão do ensino na Educação Básica, Nogueira, Pavanello, Oliveira (2012), conclui que os professores polivalentes se preocupam apenas com o ensino procedimental e não conceitual. Defendem a ideia de que não basta saber Matemática para poder ensiná-la. Tozetto, Brandt (2010), na mesma linha, frisam a importância desses professores dominarem os conteúdos a ser ensinado e conhecer profundamente o currículo proposto para sua ação pedagógica. 
Carvalho (2007), com o objetivo de melhorar o ensino de Matemática como um todo e não apenas nos anos iniciais do Ensino Fundamental, indica a necessidade de maior diálogo entre os cursos de Pedagogia e Matemática. Cardoso, Curi (2010), reforçam a necessidade de amenizar a distância entre professores polivalentes e licenciados em Matemática na formação continuada. Silva, Esteves, Souza (2010), corroborando com essa ideia, relatam que a promover a discussão entre esses cursos possibilita a integração curricular.

Sousa, Bertucci (2010), considera que a escola é um local propício para a formação continuada e a construção de grupos colaborativos para se aprimorar o ensino de conceitos matemáticos nos alunos. Silva, Vizolli (2013), Ciríaco, Morelatti (2013), da mesma forma analisam que a formação continuada em que os professores se sintam parte do processo de seu ensino-aprendizagem, proporciona reflexôes sobre a prática, possibilitando momentos de desenvolvimento profissional. No que diz respeito ao ensino, Bianchini, Nehring (2013), indicam que os professores polivalentes ao serem envolvidos neste tipo de formação desenvolvem situaçôes de aprendizagem em um contexto de temáticas compatíveis com a possibilidade de compreensão das crianças.

Os estudos, em geral, também revelam que o fato de não haver domínio de conteúdos matemáticos, os professores polivalentes não se sentem à vontade para ensinar aquilo que de fato desconhecem.

Diante destas informaçôes, segundo os artigos aqui apresentados, que os cursos de Pedagogia vêm apresentando falhas na formaçâo inicial de professores que podem comprometer o ensino de Matemática. Contudo é importante salientar a existência de resultados positivos em relação à formação continuada que condizem com a mobilização de saberes e à constituição profissional que norteiam a prática dos professores que atuam nos Anos Iniciais do Ensino Fundamental.

É considerável que sejam desenvolvidas investigações com tais finalidades, em função de identificar e compreender o que, de fato, sustenta a prática docente dos professores polivalentes para o ensino de Matemática. Finalmente, o desenvolvimento de pesquisas que tenham, por intenção, desvelar e compreender as especificidades relativas à formação do professor em questão, e possibilitar que as instituiçóes formadoras, possam identificar discutir e buscar alternativas para tais limitaçóes.

\section{Considerações finais}

Para as consideraçôes finais são apresentados momentos e aprendizagens constituídos nesse percurso de pesquisa, as limitações e dificuldades encontradas no processo de investigação, os principais resultados obtidos com este trabalho e as contribuiçôes para a ressignificação do desenvolvimento da área da formação de professores polivalentes.

Dois indicativos importantes são considerados no estudo dessa pesquisa para a formação de professores polivalentes que são: a valorização da polivalência e a questão da formação matemática nos cursos de Pedagogia relacionando à teoria e a prática. 
Em relação à valorização da polivalência, por meio deste estudo, percebe-se que a função do professor polivalente náo é considerada pelos pesquisadores, pois os autores tomam como objeto de pesquisa o ensino-aprendizagem de Matemática. Neste sentido, propóe-se que essa função passe a ser considerada na formação (inicial ou continuada) desses professores, com o objetivo de aprofundar as discussóes dessa questão nos trabalhos científicos no campo da Educação Matemática.

Outro indicativo que este trabalho trouxe é a questão da formação matemática nos cursos de Pedagogia relacionando à teoria e a prática, uma vez que podem conduzir a uma postura reflexiva do futuro professor polivalente, bem como a mudanças de paradigmas relacionados à Matemática.

Nesta pesquisa, buscamos referências para apresentar uma definição do que é a polivalência e o conhecimento matemático escolar que está envolvido na funçấo do professor polivalente, percebe-se que há poucas contribuiçôes significativas dos pesquisadores que poderiam auxiliar tendo como foco este tipo de formação. Neste sentido, observou-se que há muitas pesquisas que reconhecem esse profissional como professor de Matemática, legitimando essa atuação.

Em relação às questóes problematizadoras dessa pesquisa, podemos perceber que nos artigos é revelado pelos pesquisadores o perfil da formação matemática oferecida nos cursos de Pedagogia

Dessa maneira, refletindo sobre os artigos analisados, é possível apresentar perfis de formação matemática do professor polivalente traçados pelos pesquisadores sendo eles: (i) grande variedade de pontos de vista na formação matemática do professor polivalente; (ii) tendência em privilegiar aspectos metodológicos da Matemática; (iii) preocupação declarada com a modificação das crenças e concepções dos futuros professores sobre a Matemática, seu ensino e sua aprendizagem.

Em razão da grande variedade de ponto de vista na formação desses profissionais, acreditamos que seja importante estudar mais o que esse professor precisa saber para exercer bem o seu ofício como professor de matemática, de forma a dar elementos para se pensar no trabalho de formação a ser desenvolvido, no que diz respeito ao ensino de matemática nos Anos Iniciais considerando a polivalência.

A tendência em privilegiar aspectos metodológicos da Matemática, obviamente que práticas formadoras constituídas nestes moldes, contribui para a manutenção do quadro de má qualidade da formação docente para o ensino de matemática, o que acaba por impactar as salas de aula das turmas dos Anos Iniciais do Ensino Fundamental. Os recursos apresentados não são acompanhados normalmente de uma fundamentação que capacite o professor a utilizá-los como uma ferramenta de produção de conhecimento matemático. Dessa maneira, sem o conhecimento matemático, o futuro professor pode conhecer algumas metodologias promissoras, mas provavelmente náo conseguirá extrair delas bons resultados quando (e se) as utilizar em sala de aula.

A preocupação declarada com a modificação das crenças e concepçôes dos futuros professores sobre a Matemática, seu ensino e sua aprendizagem pelos pesquisadores permitiram ocasionar mudanças nas concepções dos professores polivalentes. Foram encontradas nas pesquisas sugestôes de modelos de formação que foram capazes de desafiar e promover alguma mudança nas crenças e concepçôes dos futuros professores, 
mostrando que esse objetivo pode ser alcançado nesta etapa, mesmo que constituam apenas o primeiro passo nessa direção. Por exemplo, estágios diferenciados, participação em diferentes atividades que promoviam a reflexão entre os futuros professores fizeram com que eles encarassem a Matemática de forma diferente da que estavam habituados. Eles puderam ver que há muitas maneiras produtivas de se trabalhar essa disciplina, não somente a tradicional.

Os pontos que ficam a desejar com o desenvolvimento dessa pesquisa são o conhecimento efetivo do professor polivalente sobre o que deve ser ensinado às crianças nas aulas de matemática e os aspectos psicológicos relacionados à maneira como elas aprendem os conteúdos. Muitas vezes, acabam sendo trabalhados conceitos tão amplos que não se estabelece uma conexão entre os conceitos matemáticos e o contexto educacional. Como consequência, a formação do professor polivalente é desconectada de sua função nos artigos apresentados.

Novos estudos sobre a função do professor polivalente podem contribuir para o desenvolvimento de novas estratégias de formação matemática para esses profissionais.

Os dados aqui expostos e analisados confirmam que essa deficiência, de fato, existe, o que nos permite sugerir o desenvolvimento de pesquisas que tenham por intenção desvelar e compreender as especificidades relativas à formação do professor em questáo. Para tanto, é indispensável que os pesquisadores se sintam instigados a investigar o assunto.

Cabe, ainda, apontar para o fato de que os eixos que constituem o conhecimento matemático escolar do professor polivalente, não podem ser concebidos como algo isolado. Os princípios e posiçóes que devem nortear as açóes que, direta ou indiretamente, estejam ligados à promoção de diferentes aprendizagens no âmbito escolar, observam-se:

- Modelos teóricos e propostas educacionais que concebem a Matemática enquanto prática social, historicamente constituída;

- A consciência da necessidade de uma reflexão em torno da polivalência, no sentido de entendê-la como parte principal da função dos professores dos Anos Iniciais do Ensino Fundamental.

Acrescenta-se, ainda, que não se pode considerar apenas a questão da pouca carga horária nos cursos de Pedagogia relacionada ao ensino de Matemática. Tendo em vista que a ação do professor polivalente está vinculada ao ensino de diferentes disciplinas, bem como o grupo de crianças pelo qual é responsável está desenvolvendo a autonomia, portanto, necessita de um olhar que contemplem esses aspectos. Referente a esses aspectos, enfatiza-se um ambiente que contemple: diálogo; brincadeira/lúdico; manipulação de objetos; interdisciplinaridade; entre outros.

Considerar a indissociabilidade com outras disciplinas e o desenvolvimento da autonomia na criança como condição do trabalho do professor polivalente, implica princípios que reforçam a relevância da relação entre os sujeitos no processo ensino-aprendizagem. Implica reconhecer a existência de um profissional que se coloca como responsável no desenvolvimento da criança como um todo. Trata-se, portanto, de um sujeito que possibilita sentidos ao processo de ensino-aprendizagem, para atender as necessidades da criança, ou seja, para servir como referência e mediador dessas açóes. Os resultados dos artigos apresentados nesta pesquisa, veiculam a ideia de que: 
- Para ensinar Matemática é preciso "saber muita Matemática”;

- Náo se aprende a ensinar num curso que oferece pouca carga horária destinada ao ensino de Matemática;

- A necessidade de formação continuada como forma de potencializar do professor polivalente.

Essas ideias não podem caminhar em direção oposta ao contexto da polivalência. A proposta é que direcionemos nossos olhares para a forma como as crianças aprendem. Também é importante compreender como o professor se situa nesse aprendizado. O desafio desse profissional não está somente no ensino de Matemática e sim no conjunto de suas atribuições que são determinantes na formação das crianças.

\section{Referências}

BATISTA, C. M. S.; SOUZA, N. M. M. Investigando as concepçóes e os anseios dos acadêmicos de Pedagogia acerca da Matemática. X ENEM, 2010.

BELINE, W. PASSOS, M. M. NAGY, M. C. CYRINO, M. C. C. T. Análise de conteúdo e os sentidos do procedimento "vai um" na operaçáo de adiçáo para formandas em Pedagogia. X ENEM, 2010.

BIANCHINI, D. F. NEHRING, C. M. Práticas estatísticas de professoras dos Anos Iniciais - uma discussáo preliminar. XI ENEM, 2013.

BULOS, A. M. M. O curso de Pedagogia e a Matemática nos Anos Iniciais. X ENEM, 2010.

CARDOSO, E. J. N. CURI, E. Perfil e opiniáo de professores dos Anos Iniciais do Ensino Fundamental de um Município do estado do Amapá com relaçáo ao ensino de Matemática. X ENEM, 2010.

CARNEIRO, R. F. A formaçáo de professores dos Anos Iniciais em um curso de Pedagogia: contribuiçóes das disciplinas de Matemática. VI SIPEM, 2015.

CARNEIRO, R. F. PASSOS, C. L. LUPIÁÑEZ, J. L.A formaçáo matemática de professores da Educação Primária na Espanha: contribuiçóes para a realidade brasileira. V SIPEM, 2012.

CARVALHO, M. Pedagogia e os conteúdos matemáticos a formaçáo do professor dos Anos Iniciais e Educaçáo Infantil. IX ENEM, 2007.

COSTA, N. M. L. Percepçóes de concluintes de Pedagogia sobre o conhecimento profissional para a docência em Matemática. IV SIPEM, 2009.

COSTA, S. C. S. CURI, E.A influência das crenças na formaçáo inicial do professor que ensina Matemática nos Anos Iniciais. X ENEM, 2010.

COSTA, S. C. S. O professor que ensina Matemática nos Anos Iniciais: limites e possibilidades de um curso de formaçáo inicial. XI ENEM, 2013.

CIRÍACO, K. T. MORELATTI, M. R. M. Desenvolvimento profissional de profess1ores iniciantes: interaçóes entre pedagogos e matemáticos. XI ENEM, 2013. 
DIAS, R. R. PAIVA, A. M. S. SÁ, I. P. A construção do pensamento geométrico na formaçáo inicial de professores da Educaçáo Infantil. XI ENEM, 2013.

LIMA, S. M. A formaçáo do pedagogo para ensinar a Matemática nos Anos Iniciais do Ensino Fundamental. XI ENEM, 2013.

MANDARINO, M. C. F. Que conteúdos da Matemática escolar os professores dos anos iniciais do Ensino Fundamental priorizam? IX ENEM, 2007.

NOGUEIRA, C. M. I. PAVANELLO, R. M. OLIVEIRA, L. A. Os professores licenciados e a Matemática dos Anos Iniciais. V SIPEM, 2012.

PALMA, R. C. D. MOURA, A. R. L. A formaçáo inicial de professores para a educaçáo infantil e Anos Iniciais do Ensino Fundamental: o movimento da produçáo de sentidos sobre os conhecimentos matemáticos. X ENEM, 2010.

POZZOBON, M. C. C. HECK, M. F. As práticas de ensino de Matemática para a formação do professor de Anos Iniciais em um curso de Pedagogia nas décadas de 1980 e 1990. XI ENEM, 2013.

OLIVEIRA, A. T. C. C. Saberes e práticas de formadores de professores que vão ensinar Matemática nos Anos Iniciais. IV SIPEM, 2009.

QUINTAS, L. P.Formaçáo continuada de professores e a resolução dos problemas matemáticos nas séries iniciais. IX ENEM, 2007.

SILVA, R. G. ESTEVES, A. K. SOUZA, N. M. M.Aproximaçóes em processo na formaçáo inicial de professores que ensinam Matemática na escola fundamental. X ENEM, 2010.

SILVA, D. I. O. VIZOLLI, I. Conhecendo a formaçáo dos professores que ensinam Matemática nos Anos Iniciais do Ensino Fundamental no município de Colinas do Tocantins.XI ENEM, 2013.

SOARES, G.Formação matemática oferecida no curso de Pedagogia: revelando olhares. XI ENEM, 2013.

SOUSA, M. C. BERTUCCI, M. C. S. Formação continuada de professores que ensinam Matemática nos Anos Iniciais: práticas desenvolvidas na escola. X ENEM, 2010.

SOUSA, A. C. G. SILVA, M. A. BARRETO, M. C.Formaçáo de professores dos Anos Iniciais do Ensino Fundamental e representaçóes semióticas: uma experiência contemplando números e operaçóes. X ENEM, 2010.

TOZETTO, A. S. BRANDT, C. F. Letramento para a docência em Matemática nos Anos Iniciais do Ensino Fundamental. X ENEM, 2010.

VASCONCELLOS, M. BITTAR, M.A formação dos professores que ensinam Matemática na Educaçáo Infantil e nos Anos Iniciais: um estudo sobre a produçáo dos eventos realizados no ano 2006. IX ENEM, 2007.

VENÂNCIO, M. M. M. VIANA, O. A. Atitudes em relaçáo à geometria de alunos do curso de Pedagogia. X ENEM, 2010. 